\title{
Analysis of the cross-border paperless trade mutual recognition cases and attributes for a cross-border mutual recognition arrangement
}

\author{
*Sung-Heun Ha, Department of Smart Convergence Consulting, Hansung University 02876, Korea , \\ ramaku@outlook.com \\ Yen-yoo You, Department of Smart Convergence Consulting, Hansung University 02876, Korea \\ *Corresponding Author
}

\begin{abstract}
Even with the increasing implementation rate of overall trade facilitation measures, crossborder paperless trade measures implementation rate has been lowest. Emerging cross-border ecommerce platforms has enabled electronic transactions hence opening a new chapter of international trade. However, the electronic means used by the private economic operators in international trade are not recognized by the public sector. The new UN Framework Agreement on the Facilitation of Crossborder Paperless Trade (2016) is one of the initiatives to overcome this barrier. However, this treaty does not provide any specific mutual recognition model yet.

This study aims to analyze a common structure and attributes that compose a cross-border mutual recognition scheme and help policymakers and practitioners establish adequate mutual recognition arrangement (MRA). From the literature review and the analysis of actual MRA cases, the study identified six attributes: normative sources, mutual recognition methods, technical possibility, management/control possibility, trust mechanism and coverage of recognition service. By applying different combinations of these attributes, MRA models with different characteristics and levels could be generated.
\end{abstract}

Keywords: Cross-Border Paperless Trade, Cross-Border Mutual Recognition Agreement, Trade Facilitation

Received: 14.12 .2020

Accepted: 10.01 .2021

Published: 03.02.2021

\section{INTRODUCTION}

After the WTO TFA, many countries across the globe have come up with policies to facilitate trade and measures to implement it. Even the overall implementation levels are varying, the global average implementation rate of the trade facilitation measures included in the UN's global survey reached $62.7 \%$ in 2019. [1] Out of five trade facilitation measure groups, the implementation rate of cross-border paperless trade has been lowest since 2017. [Ibid] Cross-border paperless trade requires a certain trust level among public and private participants. Some countries have national infrastructures to provide trusted paperless interaction, and they tend to be based on national legislation and may apply different technologies. Emerging cross-border e-commerce platforms has enabled electronic transactions hence opening a new chapter of international trade. However, the electronic means used by the private economic operators in international trade are not recognized by the public sector. Consequently, economic operators face obstacles when they engage in paperless trade across borders. Trade-related documents and data in electronic means should be exchanged and utilized across borders to serve its intended purpose, despite its electronic format. There are several initiatives in different forms to overcome barriers to mutual recognition of electronic documents and data. The new UN Framework Agreement on Facilitation of Cross-border Paperless Trade (FA-PT, 2016) is one case. But still, the promotion and wide use of such initiative, still far and studies about cross-border mutual recognition on electronic data and document cases are rare. This study aims to provide a common structure and attributes that compose a cross-border mutual recognition scheme and help policymakers and practitioners establish an adequate mutual recognition scheme for forthcoming bilateral or multilateral mutual recognition arrangements.

\section{Materials and Methods}

This study reviews previous researches regarding the cross-border mutual recognition and interoperability and summarizes layers and attributes of models by researches. Then the study analyzes 
the existing cross-border mutual recognition for paperless trade cases. By comparing the mutual recognition cases and attributes from literature, the study selects cross-border mutual recognition attributes that are distinct from other general international arrangements.

\section{Related works}

In the FA-PT, mutual recognition means "reciprocal recognition of the validity of trade-related data and documents in electronic form exchanged across borders between two or more countries". [2] The paperless trade measures in RTAs has been magnified since 2005, and most of the recent RTAs are adapting measures regarding exchanging trade-related data and information in electronic forms. [3] The new UN FA-PT provides a useful multilateral framework for cross-border mutual recognition. [Ibid.] And FA-PT has earned a reputation as "a regional digital complement to the WTO Trade Facilitation Agreement". [Ibid] Harmonization, standardization, mutual recognition, and interoperability are useful methodologies for interconnecting heterogeneous objects. [4] But these schemes are closely related but are not interchangeable. [5] Mutual recognition is a tool for cooperation among regulatory bodies. Meanwhile, harmonization, equivalence, or external criteria such as international standards are methods for introducing regulatory conformity. [Ibid] Parties to a mutual recognition arrangement agree to recognize and accept each other's mutual recognition objects because "they are harmonized or judged to be equivalent, or because they satisfy other agreed-upon external criteria". And the objective(s) of mutual recognition agreement could be "conformity assessment results, certificates, standards, regulations, quality assurance system standards, etc.". [Ibid] Agudo J. suggested that mutual recognition is composed of the same structuring elements: mutual trust, equivalence, and country-of-origin. [6] And each element acquires significance which determines the degree of conditionality or automaticity at the recognition phase. [Ibid] EU established the eIDAS Regulation to ensure trust in online transactions within the EU market by displacing barriers to the cross-border usage of e-ID. [7] However, there are concerns that mutual recognition could disadvantage undeveloped countries, and it is recommended that mutual recognition should be designed to be accessible by undeveloped countries. [8] Private protocols for crossborder electronic transactions are difficult to promote because of limited recognition by government agencies. [9]

Interoperability is often introduced as a higher concept of mutual recognition. However, most mutual recognition schemes include technical interoperability guidelines as a lower-level material for a mutual recognition policy implementation. Due to the limited studies on the mutual recognition schemes, this study reviewed the studies on the interoperability concept as well, as two concepts are similar and in complementary relations. Palfrey and Gasser proposed that interoperability can be identified on four layers of systems: 1) technology layer to transfer and render data and other information across systems, 2) applications or components layer, 3) data layer to read the data and 4) human elements layer to communicate. [10] Gilbert LaVean introduced a spectrum of interoperability model, and he designed technical possibility and management/control possibility as the most important measures. [11] The technical measure is from impractical to interface (level 1) to common equipment used (level 4), and the management/control measure is from complete independence between systems (level 1) to separate systems placed under common management/control (level 6). [Ibid]

Arms WY. insisted that interoperability requires cooperation at three levels: technical, content, and organizational. [12] The technical level covers formats, protocols, and security systems for messages exchange. The content level includes the data, metadata, and semantic agreements on the interpretation of the exchanged messages. And the organizational level is for the ground rules for access, for changing collections and services, payment, authentication, etc. He also grouped levels of interoperability into three: 1) Federation, 2) Harvesting, and 3) Gathering. [Ibid] Organizational Interoperability Maturity Model defined five levels of interoperability; independent, cooperative, collaborative, combined, and unified. And this model defines four attributes of organizational interoperability: 1) preparation, 2) understanding, 3) command and coordination, and 4) Socio-Cultural factors. [13] Tolk A. introduced the Level of Information System Interoperability Model, which provides the measurement of the level of connectivity in the attributes of technical interoperability. Four attributes are "1) Procedure and policy, 2) Applications, 3) Data, and 4) Infrastructure". Tolk A. later introduced the Layers of Coalition Interoperability model with emphasis that interoperability is dependent on organizational aspects as well as the technical attributes. [14] The nine layers of this model are, "1) Physical Interoperability, 2) Protocol Interoperability, 3) Data/Object Model Interoperability, 4) Information Interoperability, 5) Knowledge/Awareness, 6) Aligned Procedures, 7) Aligned Operations, 8) Harmonized/Strategy Doctrines, and 9) Political Objectives". Unlike other models that separate technical and operational interoperability, his model shows that the knowledge layer in the middle bridges technical interoperability and operational interoperability. [Ibid] Weber R. insisted that legal interoperability can "facilitate global communication, reduce costs in cross- 
border business and drive innovation" and he suggested that optimum or adequate levels of legal interoperability can be achieved by applying different regulatory models and normative sources. [15] The regulatory models are harmonization, standardization, mutual recognition, reciprocity, and cooperation. Source of laws (or normative sources) are treaty law, customs/standards, general principle, and selfregulation. [Ibid] The literature reviews are summarized in [Table 1].

Table 1 Summary of layers and levels of mutual recognition/interoperability models

\begin{tabular}{|c|c|c|c|c|}
\hline \multirow{2}{*}{ Author(s) } & \multirow{2}{*}{ Model } & \multirow{2}{*}{$\begin{array}{l}\text { Layers of the } \\
\text { model }\end{array}$} & \multicolumn{2}{|c|}{ Levels or measures of the model } \\
\hline & & & Levels & $\begin{array}{l}\text { Attributes or } \\
\text { measures }\end{array}$ \\
\hline TACD & $\begin{array}{l}\text { Mutual Recog } \\
\text { nition Agreem } \\
\text { ents }\end{array}$ & $\mathrm{N} / \mathrm{A}$ & $\mathrm{N} / \mathrm{A}$ & $\begin{array}{l}\text { - Regulatory } \\
\text { uniformity } \\
\text { 1) harmonization } \\
\text { 2) equivalence, }\end{array}$ \\
\hline Agudo J. & $\begin{array}{l}\text { Mutual Recog } \\
\text { nition Agreem } \\
\text { ents }\end{array}$ & $\mathrm{N} / \mathrm{A}$ & $\mathrm{N} / \mathrm{A}$ & $\begin{array}{l}\text { - mutual trust } \\
\text { - equivalence, } \\
\text { - country-of-origin }\end{array}$ \\
\hline $\begin{array}{l}\text { Palfrey \& } \\
\text { Gasser }\end{array}$ & $\begin{array}{l}\text { Interoperabilit } \\
\mathrm{y}\end{array}$ & $\begin{array}{l}\text { - technology, } \\
\text { - applications or comp } \\
\text { onents, } \\
\text { - data, } \\
\text { - human elements }\end{array}$ & $\mathrm{N} / \mathrm{A}$ & $\mathrm{N} / \mathrm{A}$ \\
\hline LaVean G. & $\begin{array}{l}\text { Spectrum of I } \\
\text { nteroperability } \\
\text { Model }\end{array}$ & $\begin{array}{l}\text { - technical possibility } \\
\text { - management / contr } \\
\text { ol possibility }\end{array}$ & & $\begin{array}{l}\text { - technical possibility } \\
\text { 1) interface } ~ \\
\text { 4) impractical } \\
\text { - management / } \\
\text { control possibility } \\
\text { 1) separate systems } \\
\text { placed under } \\
\text { common } \\
\text { management/control, } \\
\text { thus becoming the } \\
\text { same system } \\
\text { 6) complete } \\
\text { independence } \\
\text { between systems }\end{array}$ \\
\hline Arms WY. & $\begin{array}{l}\text { Interoperabilit } \\
\mathrm{y}\end{array}$ & $\begin{array}{l}\text { - technical, } \\
\text { - content, } \\
\text { - organizational }\end{array}$ & $\begin{array}{l}\text { 1) Federation, } \\
\text { 2) Harvesting, } \\
\text { 3) Gathering }\end{array}$ & $\mathrm{N} / \mathrm{A}$ \\
\hline $\begin{array}{l}\text { Clark T. \& } \\
\text { Jones R. }\end{array}$ & $\begin{array}{l}\text { Organizational } \\
\text { Interoperabil } \\
\text { ity Maturity } \\
\text { Model }\end{array}$ & $\begin{array}{l}\text { (1) preparation, } \\
\text { (2) understanding, } \\
\text { (3) command and coo } \\
\text { rdination } \\
\text { (4) Socio-Cultural facto } \\
\text { rs. }\end{array}$ & $\begin{array}{l}\text { 1) unified, } \\
\text { 2) combined, } \\
\text { 3) collaborative, } \\
\text { 4) cooperative, } \\
\text { 5) independent }\end{array}$ & $\mathrm{N} / \mathrm{A}$ \\
\hline Tolk A. & $\begin{array}{l}\text { Level of Infor } \\
\text { mation Syste } \\
\text { m Interopera } \\
\text { bility Model }\end{array}$ & $\begin{array}{l}\text { - Procedure and polic } \\
\text { y } \\
\text { - Applications } \\
\text { - Data } \\
\text { - Infrastructure } \\
\text { (1) Physical Interopera } \\
\text { bility }\end{array}$ & $\mathrm{N} / \mathrm{A}$ & $\begin{array}{l}\text { - Procedure and po } \\
\text { licy } \\
\text { - Applications, } \\
\text { - Data, } \\
\text { - Infrastructure }\end{array}$ \\
\hline Tolk A. & $\begin{array}{l}\text { Layers of Coa } \\
\text { lition Interop } \\
\text { erability mod } \\
\text { el }\end{array}$ & $\begin{array}{l}\text { (2) Protocol Interoper } \\
\text { ability } \\
\text { (3) Data/Object Model } \\
\text { Interoperability } \\
\text { (4) Information Intero } \\
\text { perability }\end{array}$ & $\mathrm{N} / \mathrm{A}$ & $\mathrm{N} / \mathrm{A}$ \\
\hline
\end{tabular}


(5) Knowledge/ Aware

ness

(6) Aligned Procedures

(7) Aligned Operations

(8) Harmonized/Strate

gy Doctrines

(9) Political Objectives

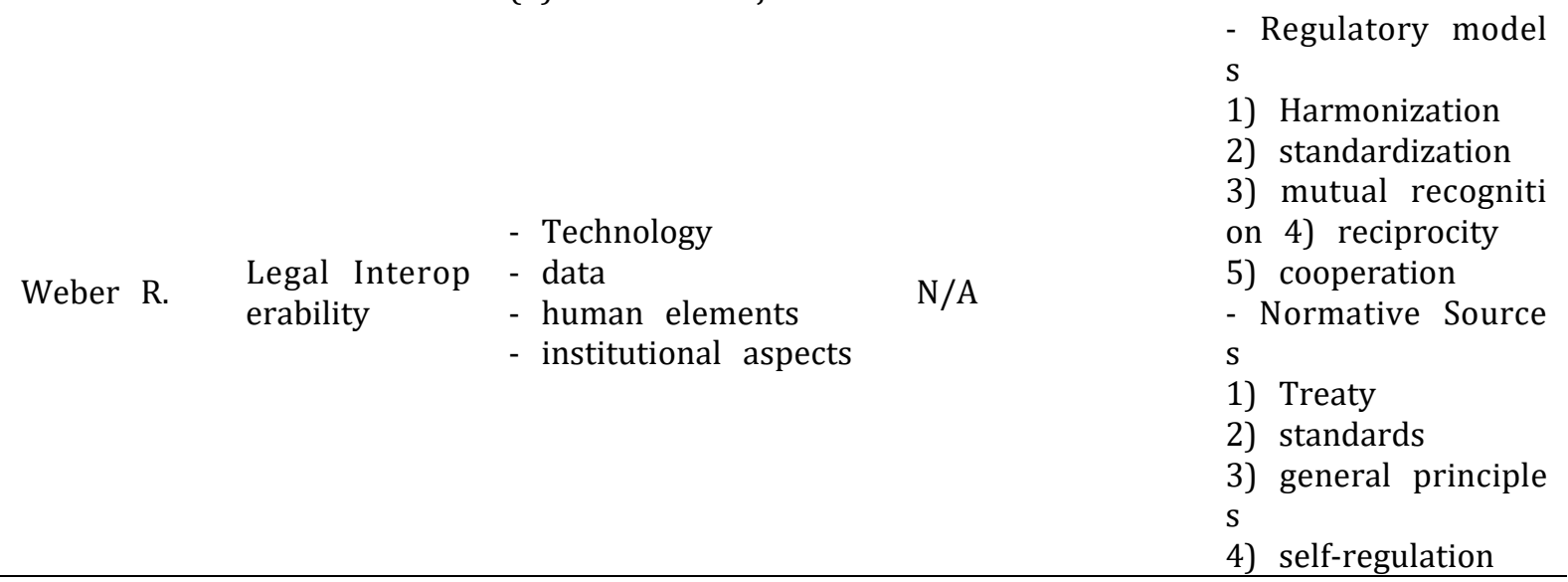

Source: author

Note: Smaller number with ')' indicates a stronger level and number with '( $)$ ' indicates an order

\section{Cross-Border Mutual recognition for Trade Facilitation}

4.1 Cross-border paperless trade mutual recognition cases

4.1.1 Pan Asian e-Commerce Alliance

PAA is an association of trade-related e-commerce service providers in Asia. PAA aims to provide seamless cross-border transaction services and has developed a robust cross-border PKI Mutual Recognition Framework to establish a comparable level of trustworthiness. Six tools define the relations among, role and responsibility of stakeholders in the PAA recognition framework. These inputs and tools are PAA Club Agreement, CPA Terms Of Reference, PAA Certificate Policy, CA Recognition Agreement, CA (and CPS) Recognition Procedure, PAA Interconnection Agreement (with Service Level Agreement) and PAA Subscriber Agreement. PAA Club Agreement is a rulebook that governs the whole recognition and cross-border transaction service framework defining the roles, responsibilities, relations, and definitions of stakeholders and tools for the framework. By signing the subscriber agreements, users agree to terms and conditions of the PAA Club Agreement, PAA PKI Mutual Recognition Framework, and PAA crossborder transaction services. The PAA Certificate Policy Authority defines the Certificate Policy (CP), and it provides the set of rules that control the procedures regarding the digital certificates and guides PAA members how to apply the certificates to their services. It provides details of the audit, revocation, archival and Certificate \& Certificate Revocation List Profiles, and others. PAA CP is the ground of PKI mutual recognition, and one of its condition is a periodical assessment of a participating Cas. Each participating CA shall ensure that their practice statement complies with PAA CP. CA Recognition Agreement is a binding arrangement between PAA CPA and each CA contracted by PAA members. Under CA Recognition Agreement, CPA recognizes that the CA is conforming to PAA requirements. PAA established CPA in 2001. The main purpose of PAA CPA is to set rules and conditions for PAA CA and CPS recognition. CPA Terms of Reference specifies the Certificate Policy of PAA and procedures of recognition of CA's CPS and a CP change management. There are minimum requirements for the recognition of trusted CA by the PAA members in the PAA CP. Applying CA's CPS is reviewed against the CP of PAA. Recognition procedures of PAA CP cover initial recognition and renewal and revocation of recognition. The initial recognition follows the below procedure:

Applying CA submits supporting documents to the Certificate Policy Authority. PAA's PKI experts review the submitted documents against $\mathrm{CP}$ and other requirements and once confirmed, PAA's PKI experts produce recommendation report to PAA Steering Committee. If accepted, the CA will enter into the recognition agreement with the PAA. PAA will add the new PAA CA to the Certificate Trust List (CTL), distribute it to PAA members and publish the CA's information to the official website.

\subsubsection{EU e-IDAS MRA}

The European Union enacted the Regulation (EU) $N^{\circ} 910 / 2014$ or electronic Identification (e-ID) and 
Authentication Services (eIDAS) Regulation, (2014), which abolishes and replaces the EU Digital Signature Directive. The EU Digital Signature Directive recommended each Member State (MS) establishes digital signature legislation, and inequality of legislation between the MS became a barrier to the formation of a single digital market. The eIDAS has a legal effect directly as national law in the MS to eliminate these obstacles and form a regional digital single market. The EU Interoperability Framework (EIF) was designed for the establishment of the single digital market by cultivating cross-border interoperability among European public services. And electronic identification (e-ID) and electronic trust services are keys for enhancing trust in an electronic transaction. The EU Digital Signature Directive recommended that each Member State establishes digital signature legislation. The eIDAS Regulation, on the other hand, has a legal effect directly as national law in a Member State without enacting a separate national law. MS that have enacted their digital signature legislation in accordance with the EU Digital Signature Directive differed from member country to country for the application of the interpretation of the electronic signature guidelines resulting in differences in the details of domestic legislation. Also, there was a problem that the supervisory system of certification service providers (certification bodies) varied between the MS. These inequality problems had been barriers to the formation of a single digital market. The eIDAS Regulations, therefore, were established to eliminate these obstacles. The mandatory mutual recognition in the region is provided only in the public service area, and it is left to the autonomous decision whether to adopt this regulation in the private area.

The key parts of the eIDAS Regulations are Chapter 2 of Electronic Identification and Chapter 3, which defines the requirements and effects of various certification services, such as the supervision and management system of certification services and electronic signature, electronic seal, and website certification. The e-ID means "the process of using person identification data in an electronic form uniquely representing either a natural or legal person or a natural person representing a legal person". [7] This e-ID is used for authentication when using the online service through e-ID cards or tokens issued through certain procedures in the individual Member States. Such mutual recognition of e-ID requires a certain trust system and Article 6 of the Regulations states that "when an e-ID and authentication is required under national law or by administrative practice to access an online service provided by a public sector body in one Member State, the e-ID means issued in another Member State shall be recognized in the first Member State, provided that certain conditions are met".

The interoperability framework components cover a reference to the assurance levels with minimum technical requirements, security standards, comparison of notified national e-ID schemes assurance levels to the eIDAS assurance levels, a meta data set uniquely representing the identification of a person either legal or natural, and dispute resolution rules. And the eIDAS requires the Member States to maintain a certain level of procedures and assurance to keep the trust among them. However, eIDAS does not define the technical electronic Identification means to achieve interoperability for electronic Identifications and electronic Trust Services. Instead, eIDAS defines the levels of assurance for trust service implementation. Commission Implementation Decision (EU) 2015/296 establishes procedures for coordination between the Member States on e-ID. The core of the decision 2015/296 is 'peer-reviewing process' and 'the Cooperation Network'. e-IDAS defines peer reviewing in four levels: relevant documentation assessment, processes review and verification, technical competency seminars and the assessment by independent third party. The Cooperation Network reviews draft notification provided by the Member States and report review result about the level of compliance of the national e-ID scheme against the EIF. Unlike the Digital Signature Directive, under the eIDAS Regulation, each Member State shall designate a supervisory body to oversee the certification work in its country and notify the body to the European Commission.

\section{Discussion}

\subsection{Attributes for MRAs.}

For the analysis of the level of actual MRA cases, the researchers have chosen attributes whose measures can be quantified. Interestingly, new two attributes, trust mechanism and coverage of recognition service, which are not found in the literature review, are identified during the case analysis.

Table 2 Quantitative measures of MRA attributes

\begin{tabular}{ll}
\hline Attributes of MRA & Measure \\
\hline $\begin{array}{l}\text { Normative sources } \\
\text { Mutual recognition } \\
\text { methods }\end{array}$ & 1) Treaty, 2) standards, 3) general principles, 4) self-regulation \\
Technical possibility & $\begin{array}{l}\text { 1) Harmonization 2) equivalence, 3) external criteria, 4) cooperation } \\
\text { interoperable systems, 3) Multiple Entry Points or gateways, 4) Separate } \\
\text { systems (programs) }\end{array}$
\end{tabular}


Management/control possibility (Integrity of the MR Implementation body is 1) completely subordinate to, 2) highly governing body and the subordinate to, 3) loosely subordinate to, 4) completely separated from implementation body)

Trust mechanism

the MR governing body

1) External evaluation, 2) Peer review, 3) self-review,

Coverage of recognition 1) Mandated to use in the public domain, 2) highly recommended using in service $\quad$ the most public domain, 3) adopted by one or a few public authorities, 4) private domain only

Together with selected four attributes, newly identified attributes are applied to two MRA cases for a measurement of the level of mutual recognition.

Table 3 Comparison of MRAs

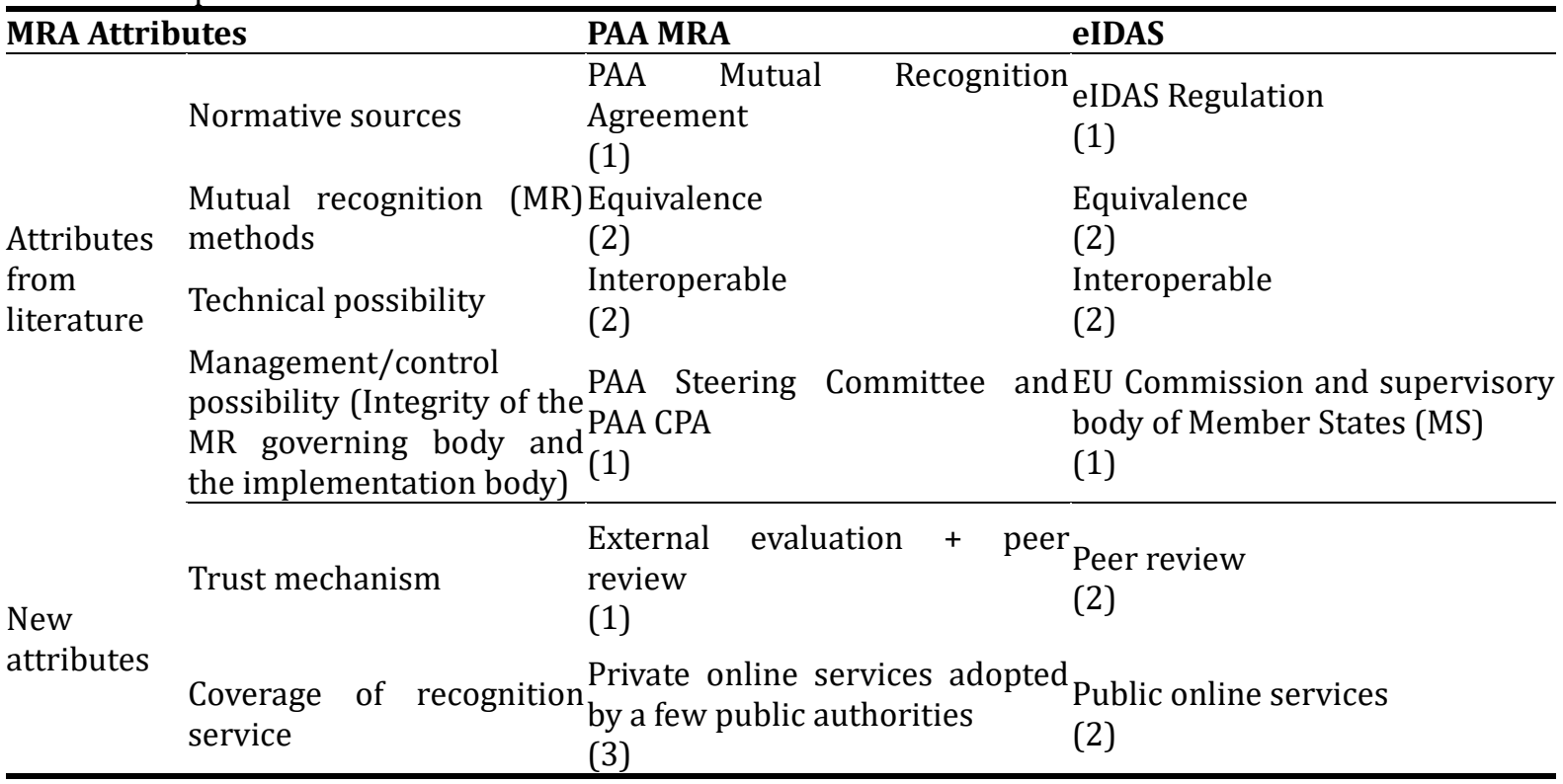

The nature of two MRAs is quite alike, considering that both are aiming promotion of cross-border electronic transactions, and both initiatives have implemented technical interoperability for the practical realization of the cross-border services. Consequently, its level of MRA attributes is similar. In order to examine whether the found attributes express the characteristics and level of the MRAs well enough, the researcher applied the attributes to other MRAs for analysis as below [Table 4].

Table 4 Comparison of other MRAs

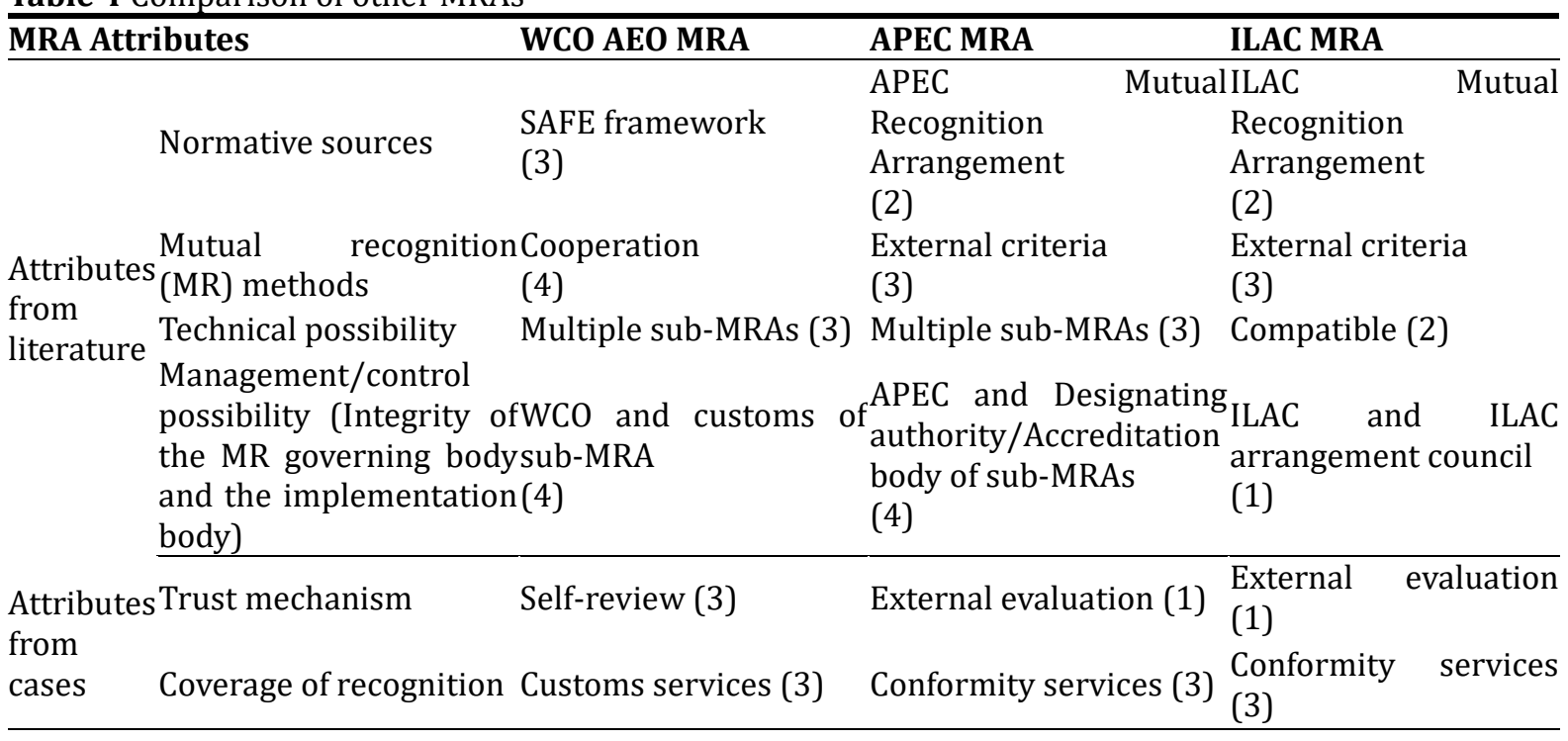

\subsection{Cross-border Mutual Recognition models}

It is possible to generate various levels of mutual recognition models by applying different values to 
the found attributes. Two sample representative MRA models at both extreme sides are generated as below.

Table 5 Sample Mutual Recognition Models

\begin{tabular}{lll} 
MR Models & $\begin{array}{l}\text { Centralized Governance } \\
\text { Model }\end{array}$ & $\begin{array}{c}\text { MRADecentralized Governance MRA } \\
\text { Model } \\
\text { (Case of eIDAS MRA) }\end{array}$ \\
\hline
\end{tabular}

\begin{tabular}{|c|c|c|}
\hline Normative sources & Treaty (1) & $\begin{array}{l}\text { General principle or self-regulation } \\
\text { (4) }\end{array}$ \\
\hline $\begin{array}{lll}\text { Mutual } & \text { recognition } & \text { (MF } \\
\text { methods } & & \end{array}$ & Equibalance (2) & Cooperation (4) \\
\hline Technical possibility & Compatible (2) & Multiple sub-MRAs (4) \\
\hline $\begin{array}{l}\text { Management/control possibilit } \\
\text { (Integrity of the MR governin } \\
\text { body and the implementatio } \\
\text { body) }\end{array}$ & gCompletely or highly subordinate & Separated (4) \\
\hline Trust mechanism & $\begin{array}{l}\text { External evaluation or peer review } \\
(1 \text { or } 2)\end{array}$ & Peer review or self-review ( 2 or 3 ) \\
\hline Coverage of recognition service & $\begin{array}{l}\text { Adopted by most public authorities } \\
\text { (2) }\end{array}$ & $\begin{array}{l}\text { A few or one authority or private } \\
\text { domain services ( } 3 \text { ) }\end{array}$ \\
\hline
\end{tabular}

\section{Conclusion}

This study examined the attributes that can express the characteristics and level of mutual recognition arrangement for cross-border paperless trade through literature reviews and case studies. Through this, six attributes (normative sources, mutual recognition methods, technical possibility, management/control possibility, trust mechanism and coverage of recognition service) are identified, and it was confirmed that these attributes could validate different MRAs. By combining different combinations of these attributes, MRA models with different characteristics and levels can be created, which will help policymakers in consideration of a new MRA scheme.

\section{Acknowledgements}

This research was supported by the research fund of the Graduate School of Hansung University.

\section{References}

[1] UN Global Survey on Digital and Sustainable Trade Facilitation 2019 [2019]. United Nations; 2019 [cited 2020 0ct 3]. Available from: https://untfsurvey.org/report

[2] Framework Agreement on Facilitation of Cross-border Paperless Trade in Asia and the Pacific, United Nations ESCAP; 2016. Available from: https://treaties.un.org/

[3] Yann D, Kong M. Digital trade facilitation: Paperless trade in regional trade agreements. ADBI Work Pap series [Internet]. 2017 Jun [cited 2020 Oct 3]; 747. Available from: https://www.adb.org/publications/digital-trade-facilitation-paperless-trade-regionaltradeagreements

[4] Trachtman JP. Embedding mutual recognition at the WTO, J Eur Public Policy. 2006 Aug 11; 14:78099

[5] TACD Briefing paper on Mutual Recognition Agreements [Internet]. Trans Atlantic Consumer Dialogue; 2001 Mar. 19 p. Available from: http://tacd.org/wp-content/uploads/2013/09/TACDTRADE-2001-Briefing-Paper-on-Mutual-Recognition-Agreements.pdf

[6] Agudo J. Mutual Recognition, Transnational Legal Relationships and Regulatory Models. Review of European Administrative Law. 2020 May. 13(1):7-40

[7] eIDAS Regulation Nº10 2014 (EU)

[8] Kelsey J. DEPA lacks added value. East Asia Forum [Internet] 2020 Apr 10 [cited 2020 Oct 3]. Available from: https://www.eastasiaforum.org/2020/04/10/depa-lacks-added-value/

[9] HA SH, Koh T. Single Window for Trade Facilitation: Regional Best Practices and Future Developments. Bangkok (TH): UNESCAP; 2018 Mar 27. 69 p.

[10] Palfrey J, Gasser U. Interop: The Promise and Perils of Highly Interconnected Systems. 1st ed. New York: Basic Books; 2012.304 p.

[11] LaVean GE. Interoperability in Defense Communications. IEEE Trans Commun [Internet]. 1980 Sep [cited 2020 Oct 3]; 28(9):1445-55 Available from: https://ieeexplore.ieee.org/document/1094832 DOI: $10.1109 /$ TCOM.1980.1094832 
[12] Arms WY. Hillmann D. LagozeC. Krafft D. Marisa R. Saylor J. et al. A Spectrum of Interoperability. Dlib Mag [Internet]. 2002 Jan [cited 2020 Oct 3];8(1) Available from: http://www.dlib.org/dlib/january02/arms/01arms.html

[13] Clark T. Jones R. Organizational Interoperability Maturity Model for C2. Proceedings of the 3rd International Command and Control Research and Technology Symposium. 1999

[14] Tolk A. Beyond Technical Interoperability - Introducing a Reference Model for Measures of Merit for Coalition Interoperability. Proceedings of the 8th International Command and Control Research and Technology Symposium. 2003

[15] Weber RH. Legal Interoperability as a Tool for Combatting Fragmentation. The Centre for International Governance Innovation; 2014 Dec. 13 p. Paper No.: 4. 